\title{
Analysis of polymorphisms in Plasmodium falciparum genes related to drug resistance: a survey over four decades under different treatment policies in Brazil
}

Juliana Inoue ${ }^{1 *}$, Dinora Lopes², Virgílio do Rosário², Marta Machado², Angélica D Hristov, Giselle FMC Lima', Maria J Costa-Nascimento ${ }^{3}$, Aluísio C Segurado ${ }^{1}$ and Silvia M Di Santi ${ }^{1,3}$

\begin{abstract}
Background: Anti-malarial resistance in Plasmodium falciparum remains an obstacle for malaria control. Resistance-associated genes were analysed in Brazilian samples over four decades to evaluate the impact of different treatment regimens on the parasite genetic profile.

Methods: Samples were collected on filter paper from patients infected in the Amazon region from 1984 to 2011. DNA was extracted with Chelex ${ }^{\circledast} 100$ and monoinfection confirmed by PCR. SNPs in the pfcrt, pfmdr1, pfdhfr and pfdhps genes were assessed by PCR-RFLP. The pfmdr 1 copy number was estimated using real time quantitative PCR with SYBR ${ }^{\odot}$ Green. Parasite response was assessed ex vivo with seven concentrations of each anti-malarial. Patients were treated according to Brazilian guidelines: quinine plus tetracycline or mefloquine in period 1 and ACT in period 2.

Results: All 96 samples presented the pfcrt 76T mutant throughout the assessed periods. In addition, all isolates showed ex vivo chloroquine resistance. The pfmdr $186 \mathrm{Y}$ was detected in $1.5 \%$ of samples in period 1 , and in $25 \%$ in period 2. All samples presented the pfmdr 1 1246Y. The analysis of pfmdr1 copy number showed amplification in $37.3 \%$ in period 1 and in 42\% in period 2. Mutations in pfdhfr were shown as follows: 511 in all samples in period 1 and in $81.2 \%$ in period 2; $59 \mathrm{R}$ in $6.4 \%$ in period 2. The pfdhfr $108 \mathrm{~N}$ and the pfdhps $437 \mathrm{G}$ were seen in all samples along time; the pfdhps 540E in $93.7 \%$ in period 1 and in $75 \%$ in period 2.

Conclusions: The 76T mutation associated to chloroquine resistance is still present in the parasite population, although this anti-malarial was withdrawn from the chemotherapy of P. falciparum in Brazil in the mid-1980s. All isolates assayed ex vivo for chloroquine showed resistant phenotype and 76T. No association was observed between pfmdr 1 mutations and resistance to quinine, mefloquine and artemisinin derivatives. Additionally, the pfdhfr $108 \mathrm{~N}$ mutation was detected in all samples throughout the evaluated periods, demonstrating fixation of the mutant allele in the parasite population. Changes in Brazilian national guidelines for the malaria chemotherapy in the last 27 years yielded a discreet genetic impact in the parasite population.
\end{abstract}

Keywords: Anti-malarial resistance, Molecular markers, Plasmodium falciparum, pfcrt, pfmdr1, pfdhfr, pfdhps

\footnotetext{
* Correspondence: julianainoue@usp.br

'Departamento de Moléstias Infecciosas e Parasitárias, Faculdade de Medicina, Universidade de São Paulo, Av. Dr. Enéas Carvalho de Aguiar, 470 sala 107, 05403-000 São Paulo, SP, Brazil

Full list of author information is available at the end of the article
} 


\section{Background}

Malaria remains a major public health concern, with the occurrence of about 207 million cases and accounting for 627,000 deaths worldwide in 2012 [1]. In Brazil 177,767 malaria cases were reported in 2013, 99.6\% of which were acquired in the Amazon region, the main endemic area for the disease in South America. In terms of species distribution, Plasmodium vivax accounted for $82 \%$ of Brazilian malaria cases, followed by Plasmodium falciparum (16.5\%) and mixed infections (1.5\%) [2]. Previously, there has been higher prevalence of $P$. falciparum [1]. However, P. falciparum is known to cause most complicated clinical cases and to have become resistant to almost all anti-malarial drugs.

Chloroquine-resistant $P$. falciparum was initially reported in Brazil in the 1960s [3] and thereafter in other South American countries [4]. Further similar cases were reported in Brazil in the 1980s in the states of Amazonas and Maranhão [5,6]. For this reason, an alternative therapeutic regimen that combined sulphadoxine and pyrimethamine (SP) was adopted as the first line treatment recommendation. However, resistance to SP was reported in northern Tocantins State soon after its use was implemented [7]. In 1982, resistance to SP was also described in other Brazilian states, such as Rondônia, Pará, Amazonas and Mato Grosso [8,9]. Subsequently, Boulos et al. [10] reported $100 \%$ of therapeutic failure to SP in 54 patients, and in the 1980s quinine in combination with tetracycline was introduced as first-line treatment. Mefloquine was incorporated in the 1990s as a new tool to treat resistant $P$. falciparum malaria, but the emergence of chemoresistance [11] led to the adoption of new strategies, such as artemisinin-based combination therapy (ACT), as recommended by the WHO in order to refrain the spread of resistance [12]. In Brazil, since 2006 the first-line treatment recommendation for non-complicated $P$. falciparum infections is the use of artemether plus lumefantrine or artesunate plus mefloquine combinations [13]. Nevertheless, decreased sensitivity has already been reported in Southeast Asia [14-16], Africa [17] and South America [18].

Resistance to anti-malarials is caused mainly by drug pressure and selection of mutated parasites, and in most cases single nucleotide polymorphisms (SNPs) in the parasite genome are involved. Resistance to chloroquine has been shown associated to SNPs in the $P$. falciparum chloroquine resistant transporter gene $(p f c r t)$ on chromosome 7 . Substitution of a lysine by threonine at codon 76 was found in resistant parasites and, therefore, this mutation has been used as a molecular marker for chloroquine resistance $[19,20]$ for both in vitro and clinical resistance assessment [21]. Substitution of amino acids (T, N or I) in the pfcrt mutant alters the electric charge of the membrane, leading to chloroquine efflux from the digestive vacuole $[22,19]$.

The $P$. falciparum multidrug resistant gene ( $p f m d r 1)$ on chromosome 5 encodes the P-glycoprotein homologue- 1 located in the parasite food vacuole and it is believed to be associated to resistance to several anti-malarials [23]. Substitution of asparagine by tyrosine at codon 86 has been shown associated with chloroquine and quinine resistance, and increased sensitivity to mefloquine and artemisinin derivatives [24]. Reed et al. [23] suggested that amino acid change in position 1246 influences response to mefloquine, quinine, halofantrine and artemisinin and modulates sensitivity to chloroquine. Price et al. [25] reported an association between increased $p f m d r 1$ copy number and risk of clinical failure with mefloquine when used in monotherapy or in combination with artesunate. Parasites with increased pfmdr1 copy number presented higher median $\mathrm{IC}_{50}$ values of mefloquine, artemisinin derivatives, quinine and lumefantrine [25-27]. However, some authors did not find a correlation between increased pfmdr1 copy numbers and mefloquine resistance [28,29].

Pyrimethamine and sulphadoxine are antifolate drugs that act by inhibiting the dihydrofolate reductase and dihydropteroate synthase enzymes, respectively. Pyrimethamine resistant $P$. falciparum presents a substitution of serine by asparagine at codon 108 of the pfdhfr gene that encodes the dihydrofolate reductase enzyme. Additionally, resistant parasites may present N51I and C59R mutations in this gene [30,31]. The A437G mutation in the $P$. falciparum dihydropteroate synthase (pfdhps) gene confers resistance to sulphadoxine. Additionally, other mutations at codons 436, 540, 581, and 613 are responsible for high level of resistance [32]. The quintuple mutation (108N/51I/59R and $437 \mathrm{G} / 540 \mathrm{E}$ ) in these two genes is considered a marker of resistance to SP [33].

The continuous monitoring of molecular markers is a very useful tool for malaria control, since it may guide therapeutic policies. Several studies have assessed allele frequencies in different time periods in Africa and Asia $[34,35]$. In some scenarios, changes in chemotherapy guidelines have led to a decline in the frequency of mutant alleles after drug pressure was withdrawn [36]. In this sense, it is important to investigate the genotypic resistance profile of parasite populations submitted to different drug pressures along time when different therapeutic regimens were employed. This survey is of particular importance for Brazilian isolates monitoring since this country accounts for $52 \%$ of reported malaria cases in the Americas [1]. This study aimed at describing the occurrence of mutations in the pfcrt, pfmdrl, pfdhfr and pfdhps genes over four decades, when the parasite population was exposed to selective pressure of various therapeutic approaches. 


\section{Methods}

\section{Study setting and ethics}

Samples were collected from patients admitted to health services in São Paulo, SP and Santarém and Alenquer, PA, with clinical malaria acquired in the Brazilian states of Acre, Amapá, Amazonas, Mato Grosso, Pará, Rondônia and Roraima. These states are located in the Amazon basin, northern Brazil, where malaria transmission occurs mainly during the dry season. Additionally, samples from subjects infected in French Guiana, Guyana and Suriname, countries bordering Brazil, were included (Figure 1). Most of the latter cases were seen in Brazilian miners who worked in bordering countries and returned to Brazil for diagnosis and treatment. The number of samples from each decade reflects epidemiological aspects of malaria in Brazil, with fluctuations in the incidence of the disease over the years, as influenced by the implementation of agricultural settlement projects and gold mining activities [37]. Ethical approval for the study was obtained from CONEP/Ministry of Health, Brazil (206/2012), and all subjects gave informed consent for participation and sample collection.

\section{Study population and blood sample collection}

Inclusion criteria required $P$. falciparum single infection diagnosed by microscopy with any parasitaemia in subjects of any age. Samples were collected from 1984 to 2011. Samples obtained from 1984 to 2009 were stored in the Malaria Laboratory/SUCEN/IMTSP biobank in liquid Nitrogen. After thawing, $50 \mu \mathrm{L}$ were plotted on Whatman $3^{\oplus}$ filter paper (Sigma-Aldrich ${ }^{\oplus}$, St. Louis, MO, USA) in duplicate. Samples from 2010 and 2011 were collected

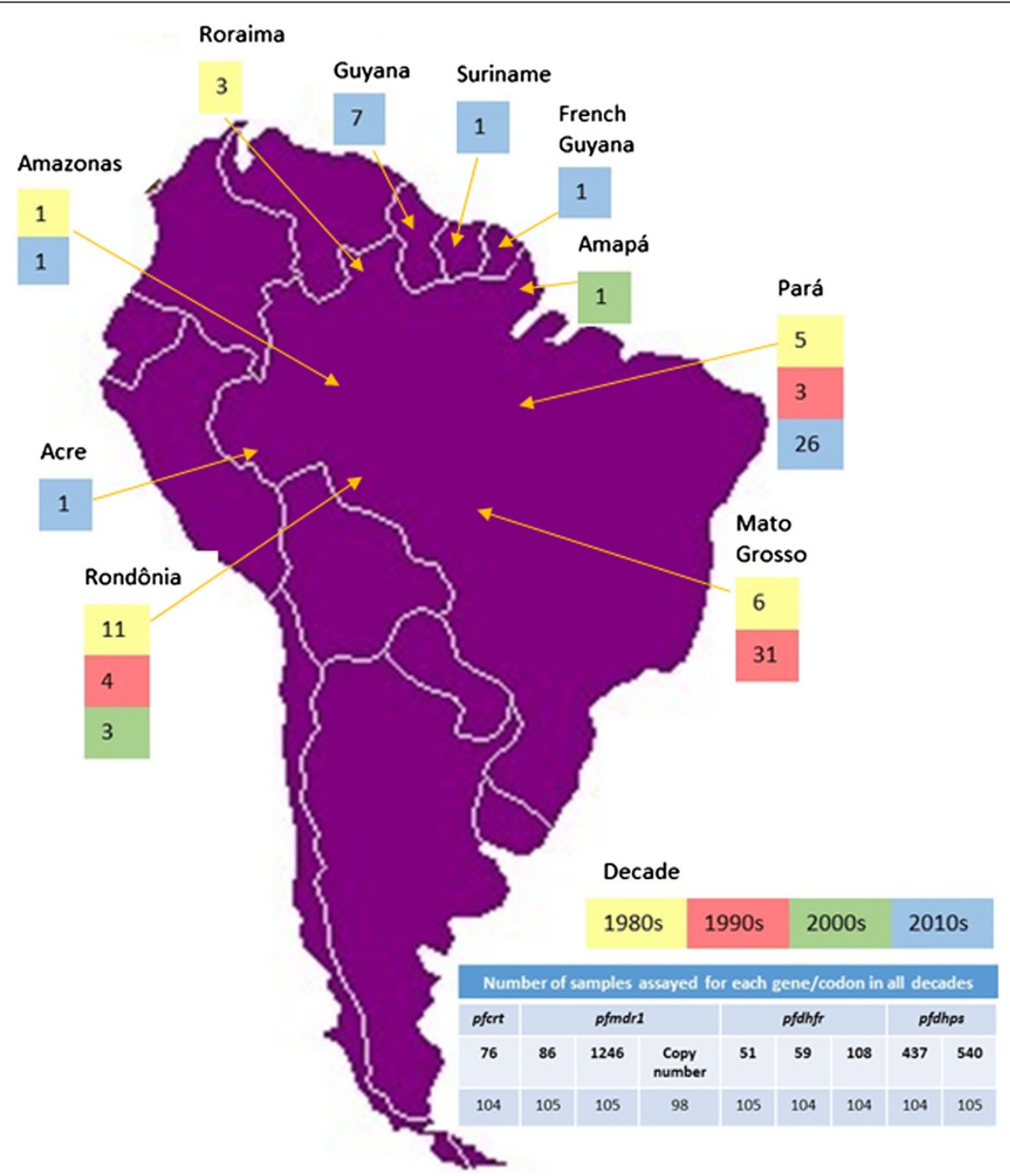

Figure 1 Distribution of $P$. falciparum samples collected from 1984 to 2011 according to site of infection. In the detail, the number of samples assayed for pfcrt, pfmdr1, pfdhfr and pfdhps. 
directly on filter paper by finger printing and stored at room temperature until use. Although samples are presented by decade of collection, the study population was analysed according to the Brazilian national therapeutic guidelines for malaria chemotherapy in use in the first two decades (quinine plus tetracycline or mefloquine) and in the last two decades (ACT), named periods 1 and 2 , respectively.

\section{Molecular identification of Plasmodium species}

DNA from filter paper was extracted with Chelex $^{\circ} 100$ (Bio-Rad ${ }^{\mathrm{Tw}}$, Hercules, CA, USA) according to the protocol by Plowe et al. [38] and stored at $-20^{\circ} \mathrm{C}$ until use. To confirm single infection by $P$. falciparum, nested PCR targeting ssrRNA genes was performed following published protocols [39].

\section{Detection of pfcrt, pfmdr1, pfdhfr and pfdhps genotypic polymorphisms}

PCR followed by restriction fragment length polymorphism analysis (RFLP) was performed to search for SNPs at codons 76 of pfcrt; 86 and 1246 of pfmdr1; 51, 59 and 108 of pfdhfr, and 437 and 540 of pfdhps genes. For pfcrt 76 and pfmdr1 86, fragments of 206 and $504 \mathrm{bp}$, respectively, were amplified by PCR and submitted to enzyme digestion with ApoI. For pfmdr1 1246, a 508 bp fragment was amplified and digested with Eco321. Fragments of 206, 326 and 522 bp were amplified for codons 51, 59 and 108 of pfdhfr and of 438 bp for both 437 and 540 codons of pfdhps gene. Digestion was performed with TasI, PdmI, AluI for codons 51, 59 and 108 of pfdhfr and with HpyF1OVI and BsegI for codons 437 and 540 of pfdhps gene. DNA samples from P. falciparum clones 3D7, Dd2 and $\mathrm{Hb} 3$ were used as controls. After RFLP, digestion products were loaded onto ethidium bromide-stained $1 \times$ TBE $2 \%$ agarose gels, and fragment sizes measured visually based on a $100 \mathrm{bp}$ DNA ladder and compared to control fragments [40-42].

\section{Determination of pfmdr 1 copy number}

Real time quantitative PCR was performed with $\mathrm{iQ}^{\mathrm{in}}$ SYBR $^{\circ}$ Green Supermix (Bio Rad ${ }^{\mathrm{m}}$, , Hercules, CA, USA) to determine pfmdrl gene copy number. Reactions were assayed in iCycler iQ Multicolor Real-Time PCR Detection System (Bio Rad ${ }^{\mathrm{m}}$, , Hercules, CA, USA), with a 10-minute incubation at $95^{\circ} \mathrm{C}$, followed by 40 cycles with 15 seconds $95^{\circ} \mathrm{C} / 1$ minute $60^{\circ} \mathrm{C}$. The melting curve was obtained with one 10-minute cycle at $95^{\circ} \mathrm{C}$. Samples were assayed in triplicate, following a published protocol [43]. The $2^{-\Delta \Delta \mathrm{Ct}}$ method was applied to estimate the pfmdr1 copy number, using DNA of two calibrators with known copy numbers (3D7, harbouring one copy and Dd2, four copies). The housekeeping gene pfßactin1 was used as recommended in order to normalize data.

\section{Ex vivo anti-malarial sensitivity test}

Twenty-two samples were assayed by ex vivo chemosensitivity tests. Samples were collected in São Paulo, regardless of site of malaria acquisition, during the two first decades, period when quinine plus tetracycline and mefloquine were employed. Samples from patients who received any anti-malarial drug in the previous 30 days before sample collection were excluded. Each sample was assayed with chloroquine, quinine and mefloquine to determine Minimal Inhibitory Concentrations (MIC). Isolates were exposed to different drug concentrations in serial dilutions for 72 hours in pre-dosed microplates, as follows: 10, 20, 40, 57, 80, 160 and $320 \mathrm{nM}$ chloroquine, $40,80,160,320,640,1280$ and $2560 \mathrm{nM}$ quinine and 5, $10,20,40,57,80$ and $160 \mathrm{nM}$ mefloquine. Infected blood was added to RPMI complete medium in $10 \%$ hematocrit, in $5 \% \mathrm{CO}_{2}, 5 \% \mathrm{O}_{2}$ and $90 \% \mathrm{~N}_{2}$ atmosphere in a $37^{\circ} \mathrm{C}$ incubator. Drug response was assessed counting the number of schizonts/200 parasites in Giemsa-stained thick blood films, using microcultures carried out in the same conditions but without exposure to anti-malarial drugs as controls. In addition, reference $P$. falciparum Palo Alto and $\mathrm{K} 1$ isolates were used as controls for chloroquinesensitive and -resistant strains, respectively [44].

\section{In vivo treatment}

Clinical data related to treatment were obtained from medical records both at the time of diagnosis and during follow-up. All patients were treated following Brazilian national guidelines for malaria chemotherapy or approved research therapeutic protocols (artemether or artesunate in monotherapy). Recrudescent parasitaemia after use of artemisinin derivatives in monotherapy were treated according to Brazilian guidelines [13,45]. Monitoring of parasitaemia was carried out on days 3, 7, 14, 28 and 35 after treatment was started. Therapeutic regimens are presented in Figure 2.

\section{Statistical analysis}

The Fisher's Exact Test (GraphPad) was applied in search of associations between in vivo or ex vivo phenotypic responses to quinine, mefloquine and artemisinin derivatives and the presence of mutations at each codon (pfmdr1 86 and 1246). The same test was used to check for association between phenotypic response and pfmdr1 copy number. $\mathrm{P}$ values $<0.05$ were considered statistically significant.

\section{Results}

\section{Origin of samples}

A total of 96 samples from patients infected in Brazil were assessed. Twenty-six samples were collected in the 1980 s, 38 in the 1990s, four in the 2000s and 28 in the 2010s. Additionally, nine samples collected from patients 

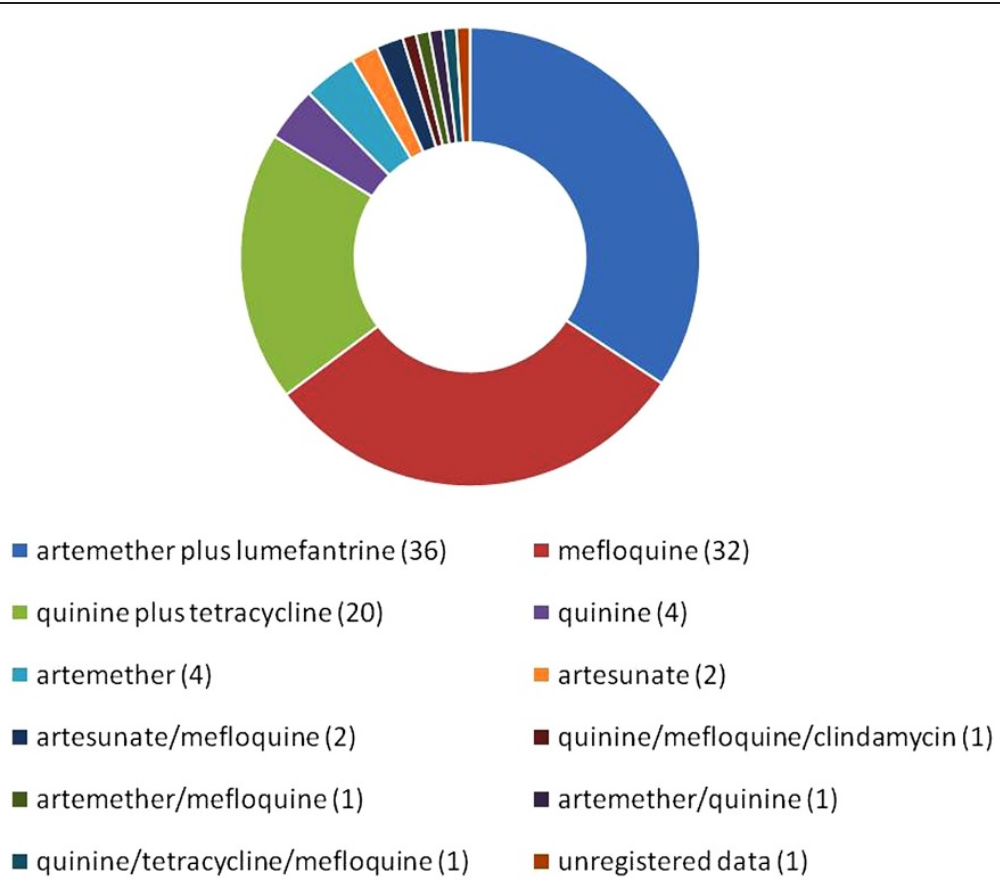

Figure 2 Therapeutic schemes in patients treated from 1984 to 2011 based on Brazilian guidelines or approved therapeutic protocols.

infected in the 2010s in countries bordering Brazil (French Guiana, Guyana and Suriname) were evaluated.

\section{pfcrt and pfmdr1}

All Brazilian samples presented the pfcrt 76T mutant in periods 1 and 2 . As for pfmdr 1 , the $86 \mathrm{Y}$ mutant was identified through in the 1990s and 2010s in different frequencies, when all but one mutant isolate harbouring the genotype $86 \mathrm{Y}$ were obtained from patients diagnosed in Pará State (Table 1). This mutant was also observed in $43 \%$ of samples collected in Pará State from patients infected in Guyana in the 2010s. All Brazilian samples as well as isolates from bordering countries presented the $1246 \mathrm{Y}$ mutant genotype in the two evaluated periods (Table 1). Assessment of pfmdr1 copy numbers from Brazilian isolates are summarized in Table 1.

\section{pfdhfr and pfdhps}

Mutations in positions 51, 59 and 108 of the pfdhfr gene are described in Table 1. Mutants at position 51 are less frequently described in period 2 and at position 59 emerged as single or mixed infections. All isolates presented the mutation in position 108 in all periods. Considering the samples from countries bordering Brazil, 8/9 presented 51I, 1/9 $51 \mathrm{~N}+\mathrm{I}$ and 1/9 $59 \mathrm{C}+\mathrm{R}$; all samples presented $108 \mathrm{~N}$ genotype. With respect to pfdhps gene, samples from both periods presented the 437G mutant genotype. At position 540, a slight decrease in the frequency of the mutant was observed (Table 1). Regarding the samples from countries bordering Brazil, all samples presented 437G and 540E.

\section{Multiple mutants}

As for multiple mutations in positions 51, 59 and 108 of the pfdhfr gene and 437 and 540 of pfdhps, 95.3\% and $4.7 \%$ of Brazilian samples from period 1 presented quadruple (ICNGE) and triple mutation (ICNGK), respectively. In period 2, it was detected quintuple mutation (IRNGE) in $12.9 \%$, quadruple ICNGE in $61.3 \%$ and IRNGK in $9.7 \%$. Triple mutation (ICNGK) was detected in $16.1 \%$, as shown in Figure 3.

Table 1 Genotyping of pfcrt, pfmdr1, pfdhfr and pfdhps in P. falciparum from Brazil, according to two distinct therapeutic regimen periods

\begin{tabular}{|c|c|c|c|c|c|c|c|c|c|c|c|c|c|}
\hline \multirow[t]{3}{*}{ Period } & \multirow{3}{*}{$\begin{array}{c}\text { pfcrt } \\
76 \\
\text { T (\%) }\end{array}$} & \multicolumn{4}{|c|}{ pfmdr1 } & \multicolumn{5}{|c|}{ pfdhfr } & \multicolumn{3}{|c|}{ pfdhps } \\
\hline & & \multirow{2}{*}{$\begin{array}{c}86 \\
Y(\%)\end{array}$} & \multirow{2}{*}{$\begin{array}{l}1246 \\
Y(\%)\end{array}$} & \multicolumn{2}{|c|}{ Copy number } & \multicolumn{2}{|r|}{51} & \multicolumn{2}{|c|}{59} & \multirow{2}{*}{$\begin{array}{c}108 \\
\mathrm{~N}(\%)\end{array}$} & \multirow{2}{*}{$\begin{array}{c}437 \\
\text { G (\%) }\end{array}$} & \multicolumn{2}{|c|}{540} \\
\hline & & & & $1(\%)$ & $>1(\%)$ & I (\%) & $\mathrm{N}+\mathrm{I}(\%)$ & R (\%) & C + R (\%) & & & E (\%) & $K+E(\%)$ \\
\hline 1 & 100 & 1.5 & 100 & 62.7 & 37.3 & 100 & 0 & 0 & 0 & 100 & 100 & 93.7 & 1.5 \\
\hline 2 & 100 & 25 & 100 & 58 & 42 & 81.2 & 18.7 & 6.4 & 16.1 & 100 & 100 & 75 & 0 \\
\hline
\end{tabular}




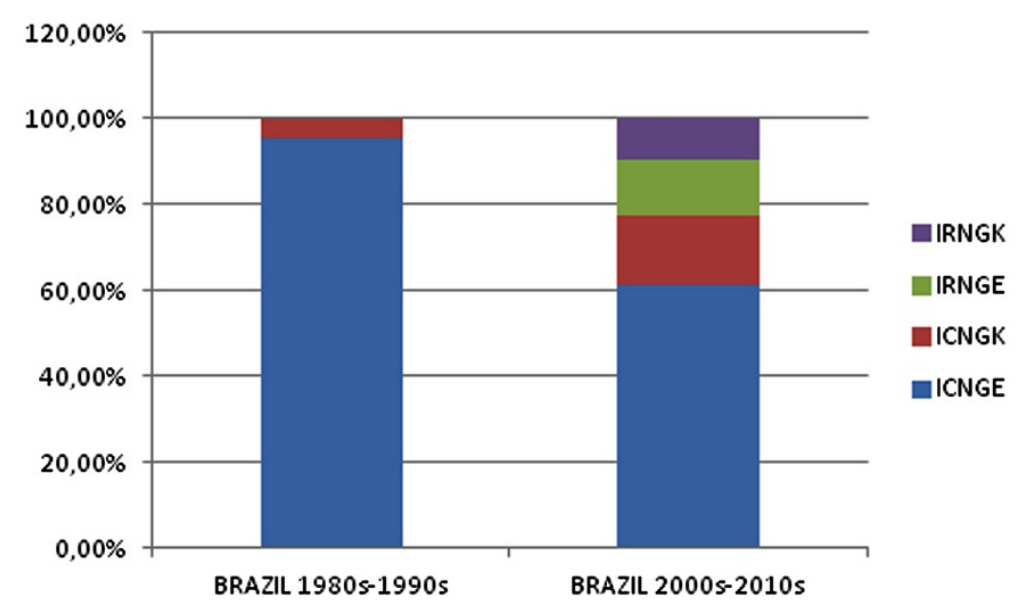

Figure 3 Distribution of quintuple (IRNGE), quadruple (ICNGE and IRNGK) and triple (ICNGK) mutations in pfdhfr and pfdhps genes in Brazilian isolates.

\section{Clinical response to chemotherapy}

Thirty-four patients who completed clinical follow-up for at least 28 days after being started on chemotherapy were evaluated. Out of these 27 had received anti-malarials following Brazilian national guidelines at time of diagnosis, six patients had been treated with artemisinin derivatives in monotherapy as subjects enrolled for a clinical research protocol, and one individual was treated with artesunate plus quinine hydrochloride due to very high parasitaemia at time of diagnosis. Patients were defined as harbouring sensitive or resistant parasites in case they exhibited absence or presence, respectively, of Plasmodium on day 28 after being started on chemotherapy. Clinical response to treatment according to therapeutic regimens is shown in Figure 4.

\section{pfcrt genotypic polymorphism versus ex vivo response to chloroquine}

Twenty-one samples were assayed for chloroquine sensitivity using an ex vivo test. All isolates showed a resistant phenotype with $\mathrm{MIC} \geq 80 \mathrm{nM}$. In addition, all samples showed the pfcrt $76 \mathrm{~T}$ mutant genotype when assayed by RFLP.

\section{pfmdr1 genotypic polymorphism versus ex vivo and in vivo responses}

Among the isolates resistant to chloroquine, one was resistant to quinine but not to mefloquine, and six were resistant to mefloquine but not to quinine. Nineteen samples were tested ex vivo for quinine sensitivity, 5.2\% of which revealed a resistant phenotype, with MIC > $2560 \mathrm{nM}$. On molecular analysis, this sample presented a wild type genotype for codon 86 and a $1246 \mathrm{Y}$ mutant. All sensitive samples presented the same genotypic profile. Ex vivo tests for mefloquine were performed in 22 samples and in $27.3 \%$ of them yielded MIC $>160 \mathrm{nM}$. The wild type genotype for codon 86 and the mutant $1246 \mathrm{Y}$ were seen in all resistant samples. One sensitive sample showed the mutant 86Y. Regarding copy numbers, out of six mefloquineresistant isolates, four presented two copies of $p f m d r 1$ and two, one copy only. Five out of 13 mefloquine-sensitive isolates showed two or more gene copies and eight out of 13, one copy only. Three isolates assayed for mefloquine showed no amplification for pfmdr1 copy number assessment.

As far as the in vivo response to chemotherapy is concerned, all patients presented a clinical recrudescence after having received quinine in monotherapy, 20\% after treatment with mefloquine and $66.6 \%$ of those who were given artemisinin derivatives in monotherapy. All these samples harboured the N86 wild genotype and the 1246Y mutant as well as those from patients who did not present recrudescent malaria.

\section{Statistical analysis}

The Fisher's Exact Test showed no association between the in vivo clinical response to quinine and the occurrence of pfmdr1 mutations in codons 86 and 1246 $(\mathrm{p}=1.000)$, neither between clinical response after chemotherapy and the pfmdr1 copy number $(\mathrm{p}=1.000)$. In addition, no association was found between the in vivo response to mefloquine and mutations in codon 86 $(\mathrm{p}=1.000), 1246(\mathrm{p}=1.000)$ or with $p f m d r 1$ copy number $(p=1.000)$. Likewise, mutations in codons 86 and 1246 or variation in gene copy number were not shown associated with in vivo clinical response to artemisinin derivatives $(\mathrm{p}=1.000)$. No statistically significant association was seen between the ex vivo response to quinine and mefloquine and $p f m d r 1$ mutations in codons 86 and $1246(\mathrm{p}=1.000)$, neither between copy number and ex vivo clinical response to mefloquine $(\mathrm{p}=0.3498)$ or quinine $(\mathrm{p}=1.000)$. 


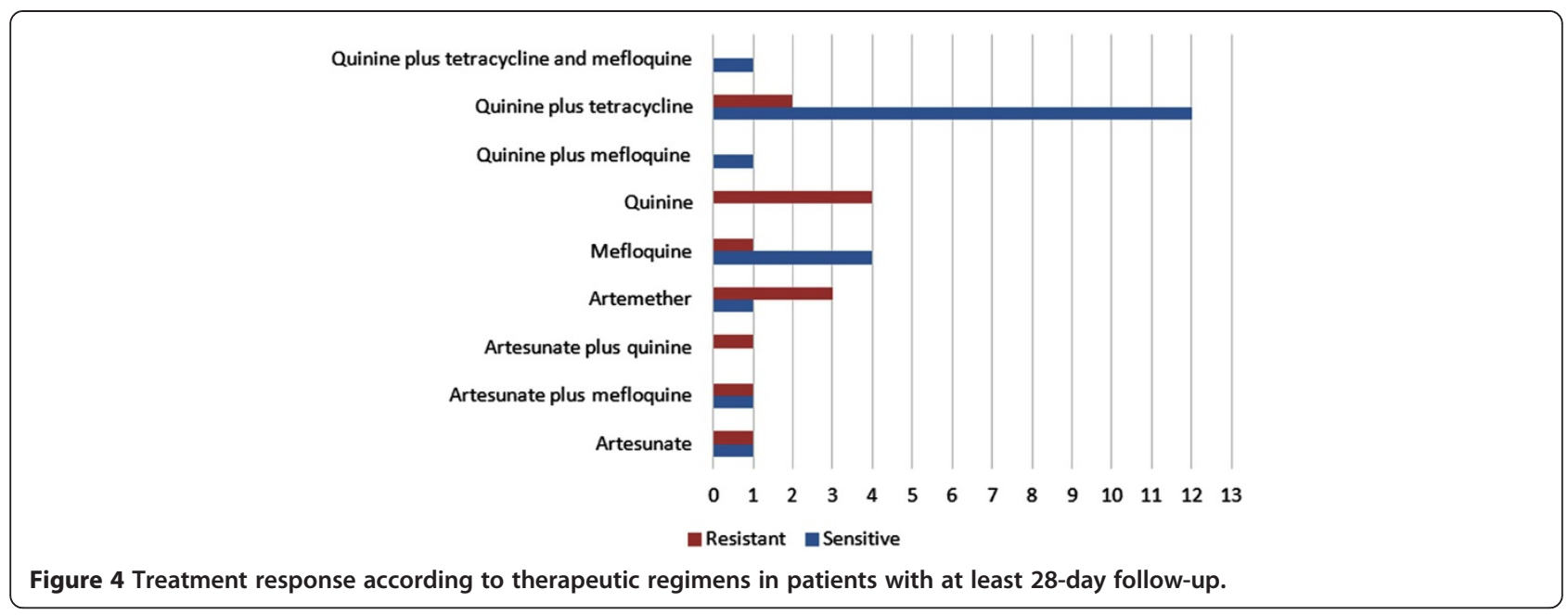

\section{Discussion}

This is the first study to assess P. falciparum genotypic polymorphisms related to chemoresistance in Brazilian samples collected over a 27-year period when different national therapeutic policies were successively in place. Analysis of $p f c r t$ gene showed that all samples harboured the $76 \mathrm{~T}$ mutation, strongly associated to chloroquine resistance, throughout the evaluated periods, even though this 4-aminoquinoline was replaced by quinine in monotherapy or associated to tetracycline in Brazilian national guidelines for malaria chemotherapy in the mid-1980s [46,47]. Assessment of pfcrt mutations is relevant to monitor molecular changes that could have led to reversal of chloroquine resistance after drug withdrawal, as seen in Malawi. In this African country, absence of drug pressure yielded restauration of chloroquine-sensitive genotypes in the parasite population [36]. A similar phenomenon occurred in Kenya with substantial reversal to the K76 genotype [48]. In Africa, P. falciparum accounts for most human malaria infections and chloroquine withdrawal after introduction of ACT removed selective drug pressure on the parasite. Such reversal, however, is not expected to take place in South America, a region characterized by high prevalence of $P$. vivax infections, which require uninterrupted use of chloroquine. In such a scenario, fixation of the mutant genotype is supported. In addition, it is important to consider that chloroquine is still widely used in this region for the treatment of rheumatic diseases including systemic lupus erythematosus, contributing to an increased drug pressure in the P. falciparum genome [49]. The results of $p f c r t$ genotyping with samples from countries bordering Brazil are in agreement with studies conducted in French Guiana [50] and Suriname [51], where therapeutic policies have been similar to those adopted in Brazil. Moreover, the molecular results are concordant with results of the ex vivo assays that revealed full resistance to chloroquine with all tested isolates.

The pfmdr 1 gene has been previously reported to be involved with increased resistance to chloroquine and quinine, and with increased sensitivity to mefloquine and artemisinins [24] or, in contrast, with increased sensitivity to quinine [52]. In this study, the N86 wild type was detected in almost all samples from periods 1 and 2, in agreement with earlier reports from Suriname [51] and other South American countries [53,54]. Considering that in period 1 Brazilian national chemotherapy guidelines recommended three different therapeutic approaches, i.e., use of chloroquine, quinine and mefloquine, it is possible to conclude that drug pressure was not able to select a mutant genotype. This hypothesis is corroborated by the lack of association between results obtained in in vivo and ex vivo assays. However, an aspect to be highlighted is the emergence of the $86 \mathrm{Y}$ mutant in the last decade of period 2 in $25 \%$ of Brazilian samples and in $43 \%$ of isolates from Guyana. Even though increased sensitivity to artemether-lumefantrine has been linked to the pfmdr1 N86 wild type in Africa [55], Bustamante et al. [56] found association between decreased sensitivity to artemether and the occurrence of the $86 \mathrm{Y}$ mutant using in vitro tests. ACT was introduced in Brazil and in Guyana in 2006. In Guyana, $P$. falciparum is the most prevalent species and a drug efficacy study showed $70.1 \%$ of patients positive at day 3 after artemether-lumefantrine treatment [57]. In gold mining and logging areas in Guyana, symptoms related to malaria are first taken care of at informal health facilities, where a wide range of anti-malarials, including artemisinin derivatives is available $[58,59]$. Taking the high flow of miners between Brazil and neighbouring countries into account, it is possible to hypothesize that the emergence of pfmdr1 $86 \mathrm{Y}$ could be related to the indiscriminate use of ACT from the mid-2000s in that 
region. Although no association was found between in vivo failure to artemisinin and the $86 \mathrm{Y}$ polymorphism, selection for this mutant requires continuous monitoring of $P$. falciparum in this region. Another relevant issue to be discussed is the fact that all samples harboured the $1246 \mathrm{Y}$ genotype throughout the evaluated periods. These results are concordant with observations by other investigators from South America, in which analysis of this codon showed only mutant parasites $[51,54]$. In conclusion, despite several changes in recommendations for malaria chemotherapy along the two periods, no genotypic selection occurred at this codon, as postulated in a study with samples from Venezuela [54].

Analysis of the pfdhfr gene showed the emergence of the $59 \mathrm{R}$ mutant in the more recent period. Additionally a high frequency of mutants at codons 51 and 108 was detected in all assessed periods. As for the pfdhps gene, a high frequency of mutants at codons 437 and 540 was observed. In Peru, removal of SP from chemotherapy recommendations was followed by reduction from $47 \%$ to $16.9 \%$ in the prevalence of the pfdhfr mutant haplotype, as well as in pfdhps with $83.8 \%$ of isolates exhibiting the wild type allele [60]. In contrast, a study conducted in Venezuela eight years after the withdrawal of SP showed resistance-associated mutations fixed in the parasite population, suggesting that in low transmission areas, fixation of resistant parasites is stable even after removal of drug pressure [61]. This scenario seems to occur in Brazil, where withdrawal of SP occurred in the 1980s. Although the emergence of codon 51 wild type allele was observed, the $108 \mathrm{~N}$ mutant is still present in the parasite population. When compared to a previous study carried out in 1991 with P. falciparum samples from the Amazon region, results of the present study show an increase of $90 \%$ to $100 \%$ in the prevalence of the pfdhfr $108 \mathrm{~N}$ mutation [62]. Such evidence discourages recommending the use of artemisinin derivatives combined with SP in Brazil. In fact, the use of artesunate plus SP in Mozambique led to a dramatic increase of mutants in a short period after the establishment of this policy [63].

Finally, all samples presented the pfcrt 76T genotype and resistance to chloroquine in those assayed ex vivo. A comparison of these results with an in vivo response was however unfeasible, as chloroquine has not been used in Brazil to treat falciparum malaria since the beginning of the first period. Nevertheless, the use of $p f c r t$ as a molecular marker for chloroquine resistance is strengthened by the present findings. Although amplification of pfindr1 has been previously associated with reduced susceptibility to mefloquine [25] and lumefantrine [64] and susceptibility to quinine [27], statistical analysis in this study did not show association between mutations in pfmdr1 codons 86 and 1246, or between pfmdr1 copy number variation with in vivo or ex vivo responses to quinine and mefloquine. The same result was observed with the in vivo response to artemisinin derivatives, in a group of patients treated outside the transmission area, without any possibility of reinfection, and followed for at least 28 days. Likewise no significant differences between ex vivo response to dihydroartemisinin, quinine and mefloquine were observed regarding pfmdr1 86 and 1246 mutations, in an African study [65]. The role of pfmdr1 in anti-malarial resistance remains thus controversial, since various epidemiological variables may differently modulate selection to which parasite populations are submitted to [66]. Furthermore, the Kelch13 gene, located on P. falciparum chromosome 13 [67] and the pfAP2 $\mu$ [68] is believed to be involved in decreased response to artemisinin derivatives.

Limitations of this study include small sample sizes for in vivo and ex vivo analyses, as well the fact that the number of samples was different in periods 1 and 2 . Nevertheless, the present report has been able to provide an idea of the extent in which different malaria chemotherapeutic recommendations used in Brazil have impacted $P$. falciparum genotypic profile in the country.

\section{Conclusions}

The pfcrt 76T mutant was demonstrated in all analysed isolates and full chemoresistance to chloroquine was shown in ex vivo response assessment. The results are also conclusive with respect to the high prevalence of pfdhfr and pfdhps mutants, indicating that SP should not be combined with artemisinin derivatives in Brazil. These findings reinforce the multidrug resistant pattern of Brazilian P. falciparum isolates. It was confirmed the fixation of 76T pfcrt, in spite of the fact that chloroquine was withdrawn from chemotherapy in the beginning of the first period considered in this study. Fixation of the mutant is believed to be due to continuous use of chloroquine for $P$. vivax infections, the most prevalent human malaria in Brazil. Likewise, mutations in pfdhfr and pfdhps genes showed no remarkable changes even after substitution of SP by different treatment regimens. Pfmdr1 presented single or multiple copies regardless of treatment policy. Analysis of SNPs in pfmdr1 showed maintenance of the molecular profile except for emergence of $86 \mathrm{Y}$ in period 2, when ACT was adopted. The lack of association between phenotypic response to quinine, mefloquine and artemisinin derivatives with SNPs in the pfmdr1 gene highlight the need for more informative tools, such as genomic wide scan, to identify polymorphisms that could be used as molecular markers of anti-malarial chemoresistance in Brazilian P. falciparum isolates.

Competing interests

The authors declare that they have no competing interests. 


\section{Authors' contributions}

$\mathrm{Jl}$ conceived the study design, carried out molecular assays, analysed all results and drafted the manuscript. DL supervised molecular studies and participated in the study design. VR contributed to the study design and revised the manuscript. MM contributed to molecular assays. ADH, GFMCL and MJCN prepared samples for molecular assays. ACS revised the manuscript. SMDS conceived and coordinated the study design, analysed al results, carried out ex vivo tests and drafted the manuscript. All authors read and approved the final manuscript.

\section{Acknowledgements}

We express our gratitude to all patients for agreeing to participate in this study and to the staff of Núcleo de Estudos em Malária/SUCEN/IMTSP, NACE-NUMETROP and Divisão de Endemias, $9^{\circ}$ Centro Regional de Saúde de Santarém/SESPA for the support in sample collection and hemoscopy and to the staff of Instituto de Higiene e Medicina Tropical/UNL for laboratory support.

This work was supported by grant \#2011/07380-8, São Paulo Research Foundation (FAPESP), Superintendência de Controle de Endemias (SUCEN), Programa de Apoio à Pós-Graduação (PROAP)/Coordenação de Aperfeiçoamento de Pessoal de Nível Superior (CAPES) and Conselho Nacional de Desenvolvimento Científico e Tecnológico (CNPq).

\section{Author details}

Departamento de Moléstias Infecciosas e Parasitárias, Faculdade de Medicina, Universidade de São Paulo, Av. Dr. Enéas Carvalho de Aguiar, 470 sala 107, 05403-000 São Paulo, SP, Brazil. ${ }^{2}$ Instituto de Higiene e Medicina Tropical, Universidade Nova de Lisboa, Rua da Junqueira, 100, 1349-008 Lisboa, Portugal. ${ }^{3}$ Núcleo de Estudos em Malária, Superintendência de Controle de Endemias/Instituto de Medicina Tropical de São Paulo, Universidade de São Paulo, Av. Dr. Enéas Carvalho de Aguiar, 470 sala 107, 05403-000 São Paulo, SP, Brazil.

Received: 10 July 2014 Accepted: 14 September 2014 Published: 19 September 2014

\section{References}

1. WHO: World Malaria Report 2013. Geneva: World Health Organization; 2013.

2. Brasil. Ministério da Saúde. Secretaria de Vigilância em Saúde/SIVEP-MALÁRIA/SVS: Casos de malária notificados entre 2011 e 2013. [http:/public.tableausoftware. com/profile/mariana.araujo\#!]].

3. Rodrigues da Silva J: Terçã maligna "cloroquino-resistente"- uma séria ameaça ao "Hinterland" brasileiro. Tribuna Médica 1961, 160:2-6.

4. Moore DV, Lanier JE: Observations on two Plasmodium falciparum infections with an abnormal response to chloroquine. Am J Trop Med Hyg 1961, 10:5-9.

5. Alecrim MGC: Resistance to in vivo and in vitro chemotherapies in the Brazilian Amazonia. Mem Inst Oswaldo Cruz 1986, 81:153-157.

6. Silva AR, Carneiro EWB, Santos HJ: Resposta dos plasmódios humanos aos antimaláricos na llha de São Luís, Estado de Maranhão, Brasil. Rev Inst Med Trop Sao Paulo 1984, 26:139-146.

7. Almeida Netto J, Oliveira G, Sampaio J: Resistência do Plasmodium falciparum à associação sulfamídicos-antifolínicos na região Centro-Oeste do Brasil; dados referentes ao estudo de 104 casos. Rev Pat Trop 1972, 1:385-393.

8. Alencar FH, Ferraroni JJ, Shrimpton R: Resistência do Plasmodium falciparum ao Fansidar, quinina e tetraciclina. Rev Saude Publica 1982, 16:299-302.

9. Alecrim MGC, Alecrim WD, Albuquerque BC, Dourado HV, Wanssa MC: Resistência do Plasmodium falciparum na Amazônia Brasileira à associação sulfadoxina + pirimetamina. Rev Inst Med Trop Sao Paulo 1982, 24:44-47.

10. Boulos M, Di Santi SM, Barata LCB, Segurado AAC, Dutra AP, Camargo Neves VLF: Some aspects of treatment, prophylaxis and chemoresistance of Plasmodium falciparum malaria. Mem Inst Oswaldo Cruz 1986, 81:255-257.

11. Cerutti C, Durlacher RR, de Alencar FE, Segurado AA, Pang LW: In vivo efficacy of mefloquine for the treatment of falciparum malaria in Brazil. J Infect Dis 1999, 180:2077-2080.

12. WHO: Guidelines for the treatment of malaria. Geneva: World Health Organization; 2010

13. Alecrim MG, Lacerda MV, Mourão MP, Alecrim WD, Padilha A, Cardoso BS, Boulos M: Successful treatment of Plasmodium falciparum malaria with a six-dose regimen of artemether-lumefantrine versus quinine-doxycycline in the Western Amazon region of Brazil. Am J Trop Med Hyg 2006, 74:20-25.
14. Dondorp AM, Nosten F, Yi P, Das D, Phyo AP, Tarning J, Lwin KM, Ariey F, Hanpithakpong W, Lee SJ, Ringwald P, Silamut K, Imwong M, Chotivanich K, Lim P, Herdman T, An SS, Yeung S, Singhasivanon P, Day NP, Lindegardh N, Socheat D, White NJ: Artemisinin resistance in Plasmodium falciparum malaria. N Engl J Med 2009, 361:455-467.

15. Dondorp AM, Fairhurst RM, Slutsker L, MacArthur JR, Breman JG, Guerin PJ, Wellems TE, Ringwald P, Newman RD, Plowe CV: The threat of artemisinin-resistant malaria. N Engl J Med 2011, 365:1073-1075.

16. WHO: Emergency response to artemisinin resistance in the Greater Mekong sub region: regional framework for action 2013-2015. Geneva: World Health Organization; 2013.

17. Färnert A, Ursing J, Tolfvenstam T, Rono J, Karlsson L, Sparrelid E, Lindegårdh N: Artemether-lumefantrine treatment failure despite adequate lumefantrine day 7 concentration in a traveller with Plasmodium falciparum malaria after returning from Tanzania. Malar J 2012, 11:176.

18. Vreden SG, Jitan JK, Bansie RD, Adhin MR: Evidence of an increased incidence of day 3 parasitaemia in Suriname: an indicator of the emerging resistance of Plasmodium falciparum to artemether. Mem Inst Oswaldo Cruz 2013, 108:968-973.

19. Fidock AD, Nomura T, Talley KA, Cooper AR, Dzekunov MS, Ferdig TM, Ursos ML, Sidhu AB, Naude B, Deitsch WK, Su ZX, Wootton CJ, Roepe DP, Wellems TE: Mutations in the $P$. falciparum digestive vacuole transmembrane protein Pfcrt and evidence for their role in chloroquine resistance. Mol Cell 2000, 6:861-871

20. Wellems TE, Walker-Jonah A, Panton LJ: Genetic mapping of the chloroquine-resistance locus on Plasmodium falciparum chromosome 7. Proc Natl Acad Sci U S A 1991, 88:3382-3386.

21. Wellems TE, Plowe CV: Chloroquine-resistant malaria. J Infect Dis 2001, 184:770-776.

22. Cooper RA, Ferdig MT, Su XZ, Ursos LM, Mu J, Nomura T, Fujioka H, Fidock DA, Roepe PD, Wellems TE: Alternative mutations at position 76 of the vacuolar transmembrane protein Pfcrt are associated with chloroquine resistance and unique stereospecific quinine and quinidine responses in Plasmodium falciparum. Mol Pharmacol 2002, 61:35-42.

23. Reed MB, Saliba KJ, Caruana SR, Kirk K, Cowman AF: Pgh1 modulates sensitivity and resistance to multiple antimalarials in Plasmodium falciparum. Nature 2000, 403:906-909.

24. Duraisingh MT, Jones $P$, Sambou I, von Seidlein $L$, Pinder $M$, Warhurst DC: The tyrosine-86 allele of the pfmdr1 gene of Plasmodium falciparum is associated with increased sensitivity to the anti-malarials mefloquine and artemisinin. Mol Biochem Parasitol 2000, 108:13-23.

25. Price RN, Uhlemann AC, Brockman A, MCGready R, Ashley E, Phaipun L, Patel R, Laing K, Looareesuwan S, White NJ, Nosten F, Krishna S: Mefloquine resistance in Plasmodium falciparum and increased pfmdr1 gene copy number. Lancet 2004, 364:438-447.

26. Cowman AF, Galatis D, Thompson JK: Selection for mefloquine resistance in Plasmodium falciparum is linked to amplification of the pfmdr1 gene and crossresistance to halofantrine and quinine. Proc Natl Acad Sci U S A 1994, 91:1143-1147.

27. Sidhu AB, Uhlemann AC, Valderramos SG, Valderramos JC, Krishna S, Fidock DA: Decreasing pfmdr1 copy number in Plasmodium falciparum malaria heightens susceptibility to mefloquine, lumefantrine, halofantrine, quinine, and artemisinin. J Infect Dis 2006, 194:528-535.

28. Basco LK, Eldin de Pecoulas P, Le Bras J, Wilson CM: Plasmodium falciparum: molecular characterization of multidrug-resistant Cambodian isolates. Exp Parasitol 1996, 82:97-103.

29. Lim AS, Galatis D, Cowman AF: Plasmodium falciparum: Amplification and overexpression of Pfmdr1 is not necessary for increased mefloquine resistance. Exp Parasitol 1996, 83:295-303.

30. Peterson DS, Walliker D, Wellems TE: Evidence that a point mutation in dihidrofolate reductase thymidylate synthase confers resistance to pyrimethamine in falciparum malaria. Proc Natl Acad Sci U S A 1988, 85:9114-9118.

31. Basco LK, Ringwald P: Molecular epidemiology of malaria in Yaounde, Cameroon. VI. Sequence variations in the Plasmodium falciparum dihydrofolate reductase-thymidylate synthase gene and in vitro resistance to pyrimethamine and cycloguanil. Am J Trop Med Hyg 2000, 62:271-276

32. Peek R, Van Gool T, Panchoe D, Greve S, Bus E, Resida L: Drug resistance and genetic diversity of Plasmodium falciparum parasites from Suriname. Am J Trop Med Hyg 2005, 73:833-838. 
33. Kublin JG, Dzinjalamala FK, Kamwendo DD, Malkin EM, Cortese JF, Martino LM, Mukadam RA, Rogerson SJ, Lescano AG, Molyneux ME, Winstanley PA Chimpeni P, Taylor TE, Plowe CV: Molecular markers for failure of sulfadoxine-pyrimethamine and chlorproguanil-dapsone treatment of Plasmodium falciparum malaria. J Infect Dis 2002, 185:380-388.

34. Nwakanma DC, Duffy CW, Amambua-Ngwa A, Oriero EC, Bojang KA, Pinder M, Drakeley CJ, Sutherland CJ, Milligan PJ, Macinnis B, Kwiatkowski DP, Clark TG, Greenwood BM, Conway DJ: Changes in malaria parasite drug resistance in an endemic population over a 25 -year period with resulting genomic evidence of selection. J Infect Dis 2014, 209:1126-1135.

35. Ahmed A, Bararia D, Vinayak S, Yameen M, Biswas S, Dev V, Kumar A, Ansari MA Sharma YD: Plasmodium falciparum isolates in India exhibit a progressive increase in mutations associated with sulfadoxine pyrimethamine resistance. Antimicrob Agents Chemother 2004, 48:879-889.

36. Laufer MK, Takala-Harrison S, Dzinjalamala FK, Stine OC, Taylor TE, Plowe CV: Return of chloroquine-susceptible falciparum malaria in Malawi was a reexpansion of diverse susceptible parasites. J Infect Dis 2010, 202:801-808.

37. Oliveira-Ferreira J, Lacerda MV, Brasil P, Ladislau JL, Tauil PL, Daniel-Ribeiro CT: Malaria in Brazil: an overview. Malar J 2010, 9:115

38. Plowe CV, Djimde A, Bouare M, Doumbo O, Wellems TE: Pyrimethamine and proguanil resistance - conferring mutations in Plasmodium falciparum dihydrofolate reductase: polymerase chain reaction method for surveillance in Africa. Am J Trop Med Hyg 1995, 52:565-568.

39. Snounou G, Viriyakosol S, Zhu XP, Jarra W, Pinheiro L, do Rosario VE, Thaithong S, Brown KN: High sensitivity of detection of human malaria parasites by the use of nested polymerase chain reaction. Mol Biochem Parasitol 1993, 61:315-320.

40. Lopes D, Rungsihirunrat K, Nogueira F, Seugorn A, Gil JP, Rosário VE, Cravo $P$ : Molecular characterization of drug-resistant Plasmodium falciparum from Thailand. Malar J 2002, 1:12

41. Figueiredo P, Benchimol C, Lopes D, Bernardino L, do Rosário VE, Varandas L, Nogueira F: Prevalence of pfmdr1, pfcrt, pfdhfr and pfdhps mutations associated with drug resistance, in Luanda, Angola. Malar J 2008, 7:236.

42. Mendes C, Salqueiro P, Gonzalez V, Berzosa P, Benito A, do Rosário VE, de Sousa B, Cano J, Arez AP: Genetic diversity and signatures of selection of drug resistance in Plasmodium populations from both human and mosquito hosts in continental Equatorial Guinea. Malar J 2013, 12:114

43. Ferreira ID, Rosário VE, Cravo PV: Real-time quantitative with SYBR Green I detection for estimating copy numbers of nine drug resistance candidate genes in Plasmodium falciparum. Malar J 2006, 5:1.

44. Di Santi SM, Camargo Neves VL, Boulos M, Dutra AP, Ramos AM, Santos M, Barata LC: Evaluation of the Plasmodium falciparum response to chloroquine, quinine and mefloquine. Rev Inst Med Trop Sao Paulo 1988, 30:147-152.

45. Brasil. Secretaria de Estado da Saúde. Superintendência de Controle de Endemias: Manual de Terapêutica de Malária. São Paulo: Secretaria de Estado da Saúde; 1998.

46. Barata LCB, Boulos M, Dutra AP: Emprego da associação tetraciclina e quinino no tratamento da malária causada pelo Plasmodium falciparum. Rev Soc Bras Med Trop 1986, 19:135-137.

47. Boulos M, Dutra AP, Di Santi SM, Shiroma M, Amato Neto V: The clinical evaluation of quinine for the treatment of Plasmodium falciparum malaria. Rev Soc Bras Med Trop 1997, 30:211-213.

48. Mang'era CM, Mbai FN, Omedo IA, Mireji PO, Omar SA: Changes in genotypes of Plasmodium falciparum human malaria parasite following withdrawal of chloroquine in Tiwi, Kenya. Acta Trop 2012, 123:202-207.

49. Raster M, Horn F, Jünemann A, Rosa AA, Souza GS, Gomes BD, Lima MG, Silveira LC, Kremers J: Retinal disorders in northern Brazilian patients treated with chloroquine assessed by multifocal ERG. Doc Ophthalmol 2011, 122:77-86

50. Legrand E, Yrinesi J, Ekala MT, Péneau J, Volney B, Berger F, Bouchier C, Bertani S, Musset L, Meynard JB, Mercereau-Puijalon O: Discordant temporal evolution of Pfcrt and Pfmdr1 genotypes and Plasmodium falciparum in vitro drug susceptibility to 4-aminoquinolines after drug policy change in French Guiana. Antimicrob Agents Chemother 2012, 56:1382-1389.

51. Adhin MR, Labadie-Bracho M, Bretas G: Molecular surveillance as monitoring tool for drug-resistant Plasmodium falciparum in Suriname. Am J Trop Med Hyg 2013, 89:311-316.

52. Phompradit $P$, Wisedpanichkij R, Muhamad $P$, Chaijaroenkul W, Na-Bangchang K: Molecular analysis of pfatp6 and pfmdr1 polymorphisms and their association with in vitro sensitivity in Plasmodium falciparum isolates from the Thai-Myanmar border. Acta Trop 2011, 120:130-135.
53. Bacon DJ, McCollum AM, Griffing SM, Salas C, Soberon V, Santolalla M, Haley R, Tsukayama P, Lucas C, Escalante AA, Udhayakumar V: Dynamics of malaria drug resistance patterns in the Amazon basin region following changes in Peruvian national treatment policy for uncomplicated malaria. Antimicrob Agents Chemother 2009, 53:2042-2051.

54. Griffing S, Syphard L, Sridaran S, McCollum AM, Mixson-Hayden T, Vinayak S, Villegas L, Barnwell JW, Escalante AA, Udhayakumar V: pfmdr1 amplification and fixation of pfcrt chloroquine resistance alleles in Plasmodium falciparum in Venezuela. Antimicrob Agents Chemother 2010, 54:1572-1579.

55. Lobo E, de Sousa B, Rosa S, Figueiredo P, Lobo L, Pateira S, Fernandes N, Nogueira F: Prevalence of pfmdr1 alleles associated with artemetherlumefantrine tolerance/resistance in Maputo before and after the implementation of artemisinin-based combination therapy. Malar J 2014 13:300.

56. Bustamante C, Folarin OA, Gbotosho GO, Batista CN, Mesquita EA, Brindeiro RM, Tanuri A, Struchiner CJ, Sowunmi A, Oduola A, Wirth DF, Zalis MG, Happi CT: In vitro-reduced susceptibility to artemether in $P$. falciparum and its association with polymorphisms on transporter genes. J Infect Dis 2012, 206:324-332.

57. WHO. World Health Organization. Malaria Policy Advisory Committee Meeting: Status of the efficacy of artemisinin-based combination therapy (ACT) in Guyana and Suriname. Geneva: World Health Organization; 2013.

58. Pan American Health Organization: Report on the Situation of Malaria in the Americas. Washington D.C: PAHO; 2010.

59. Vosti SA: Malaria among gold miners in southern Para Brazil: estimates of determinants and individual costs. Soc Sci Med 1990, 30:1097-1105.

60. Zhou Z, Griffing SM, de Oliveira AM, McCollum AM, Quezada WM, Arrospide N, Escalante AA, Udhayakumar V: Decline in sulfadoxine-pyrimethamine-resistant alleles after change in drug policy in the Amazon region of Peru. Antimicrob Agents Chemother 2008, 52:739-741.

61. McCollum AM, Mueller K, Villegas L, Udhayakumar V, Escalante AA: Common origin and fixation of Plasmodium falciparum dhfr and dhps mutations associated with sulfadoxine-pyrimethamine resistance in a low-transmission area in South America. Antimicrob Agents Chemother 2007, 51:2085-2091.

62. Peterson DS, Di Santi SM, Povoa M, Calvosa VS, Do Rosario VE, Wellems TE: Prevalence of the dihydrofolate reductase Asn-108 mutation as the basis for pyrimethamine-resistant falciparum malaria in the Brazilian Amazon. Am J Trop Med Hyg 1991, 45:492-497.

63. Raman J, Mauff K, Muianga P, Mussa A, Maharaj R, Barnes Kl: Five years of antimalarial resistance marker surveillance in Gaza Province, Mozambique, following artemisinin-based combination therapy roll out. PLoS One 2011, 6:e25992.

64. Price RN, Uhlemann AC, van Vugt M, Brockman A, Hutagalung R, Nair S, Nash D, Singhasivanon P, Anderson TJ, Krishna S, White NJ, Nosten F: Molecular and pharmacological determinants of the therapeutic response to artemether-lumefantrine in multidrug-resistant Plasmodium falciparum malaria. Clin Infect Dis 2006, 42:1570-1577.

65. Menard D, Yapou F, Manirakiza A, Djalle D, Matsika-Claquin MD, Talarmin A Polymorphisms in pfcrt, pfmdr1, dhfr genes and in vitro responses to antimalarials in Plasmodium falciparum isolates from Bangui, Central African Republic. Am J Trop Med Hyg 2006, 75:381-387.

66. Duraisingh MT, Cowman AF: Contribution of the pfmdr1 gene to antimalarial drug-resistance. Acta Trop 2005, 94:181-190.

67. Ariey F, Witkowski B, Amaratunga C, Beghain J, Langlois AC, Khim N, Kim S, Duru V, Bouchier C, Ma L, Lim P, Leang R, Duong S, Sreng S, Suon S, Chuor CM, Bout DM, Ménard S, Rogers WO, Genton B, Fandeur T, Miotto O, Ringwald P, Le Bras J, Berry A, Barale JC, Fairhurst RMBenoit-Vical F, Mercereau-Puijalon O, Ménard D: A molecular marker of artemisinin-resistant Plasmodium falciparum malaria. Nature 2014, 505:50-55.

68. Henriques G, Martinelli A, Rodrigues L, Modrzynska K, Fawcett R, Houston DR, Borges ST, d'Alessandro U, Tinto H, Karema C, Hunt P, Cravo P: Artemisinin resistance in rodent malaria - mutation in the AP2 adaptor $\mu$-chain suggests involvement of endocytosis and membrane protein trafficking. Malar J 2013, 12:118.

doi:10.1186/1475-2875-13-372

Cite this article as: Inoue et al.: Analysis of polymorphisms in Plasmodium falciparum genes related to drug resistance: a survey over four decades under different treatment policies in Brazil. Malaria Journal 2014 13:372. 